SUPPORTING INFORMATION

Novel Supramolecular Nanoparticles Derived From Cucurbit[7]uril and Zwitterionic Surfactants

J. Fernández-Rosas ${ }^{\mathrm{a}}$, Marcia Pessêgo ${ }^{\mathrm{b}}$, Angel Acuña $^{\mathrm{a}}$, Carlos Vázquez-Vázquez ${ }^{\mathrm{c}}$, Javier Montenegro $^{\mathrm{d}}$, Mercedes Parajó ${ }^{\mathrm{a}}$, Pedro Rodríguez-Dafonte ${ }^{\mathrm{a}}$, Faruk Nome ${ }^{\mathrm{e}}$, Luis Garcia$\mathrm{Rio}^{\mathrm{a} *}$

1. Design of competitive experiments for determination of sulfobetaine binding constants to $\mathrm{CB} 7$. 2

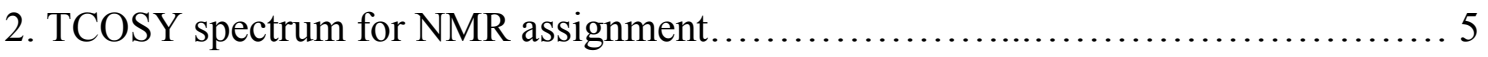

3. NMR evidence for 2:1 host:guest complexes................................ 6

4. DLS characterization of SNPs formation and disruption............................. 12

5. Size and Zeta potential evolution with time and composition....................... 14

6. DLS experiments in the presence of CF.......................................... 15

7. CF fluorescence in the presence of SB3-16 micelles............................ 16 


\section{Competitive Experiments}

The influence of $\mathrm{CB} 7$ on the absorption spectra of $\mathrm{DSMI}^{+}$in the absence of sulfobetaines was studied. The influence of the CB7 concentration on the absorption spectra is shown in Figure S1. Influence of $\mathrm{CB} 7$ concentration on the absorption spectra of DSMI,$+[\mathrm{DSMI}+]=1.17 \times 10-5 \mathrm{M}$, at neutral $\mathrm{pH}$ and $25.0^{\circ} \mathrm{C}$.

. The $\mathrm{DSMI}^{+}$has an absorption maximum centered at $444 \mathrm{~nm}$ in aqueous solution and it can be seen the absorption maximum peak decreases as increase the CB7 concentration, due to the formation of an inclusion complex (CB7-DSMI) between $\mathrm{CB} 7$ and $\mathrm{DSMI}^{+}$. The CB7 is known for high propensity to complex and stabilize protonated guests and could induce shifts of 4 units on $\mathrm{pKa}$. ${ }^{1}$ At $330 \mathrm{~nm}$ it is observed the formation of a new absorption peak, probably due to the protonation of $\mathrm{DSMI}^{+}(\mathrm{pKa}=3.1)$.
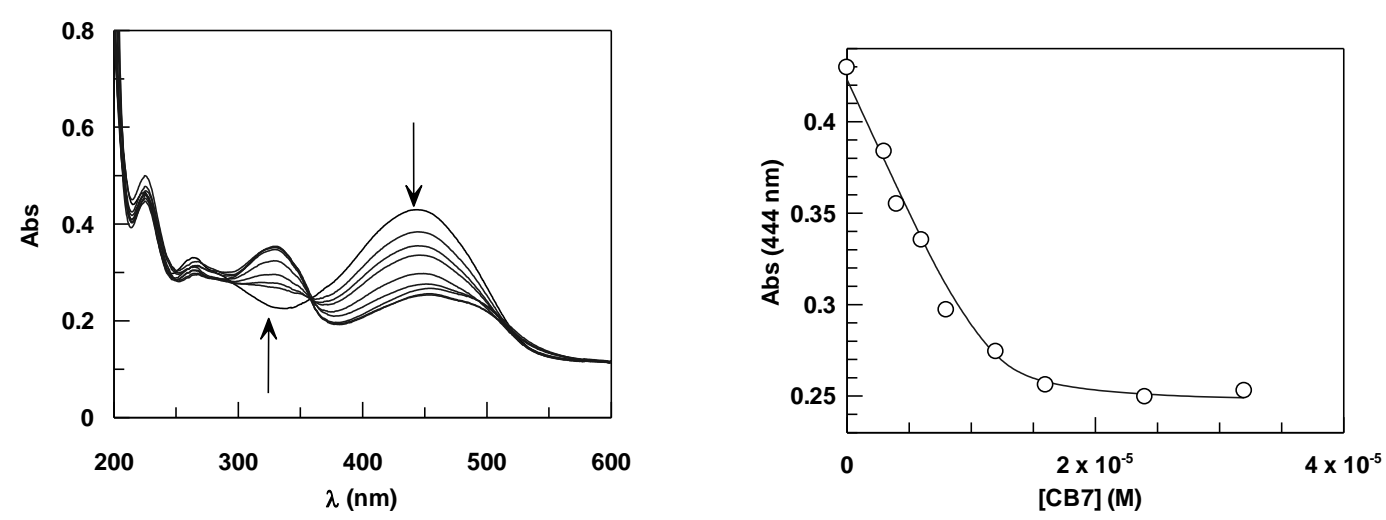

Figure S1. Influence of CB7 concentration on the absorption spectra of DSMI ${ }^{+},\left[\mathrm{DSMI}^{+}\right]=1.17 \times 10^{-5} \mathrm{M}$, at neutral $\mathrm{pH}$ and $25.0^{\circ} \mathrm{C}$.

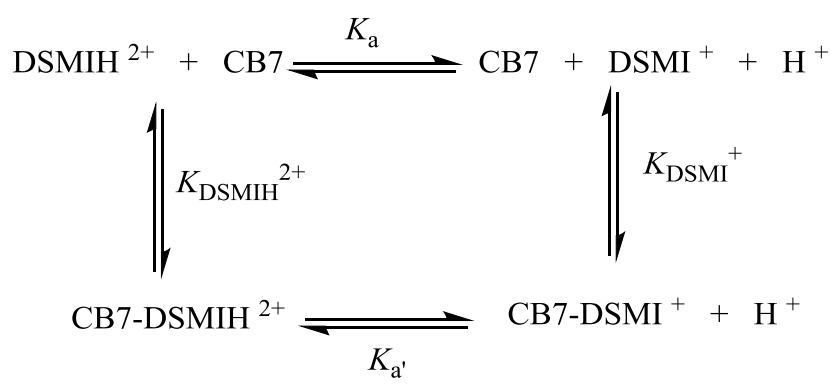

Scheme S- 1

The $A_{\text {obs }}$ at any specific wavelength is expressed as an average of all the absorbing species in the medium, that can be expressed as 


$$
A_{o b s}=\varepsilon^{D S M I+}\left[D S M I^{+}\right]+\varepsilon^{D S M I H 2+}\left[D S M I H^{2+}\right]+\varepsilon^{C B 7-D S M I+}\left[C B 7-D_{S M I}^{+}\right]+\varepsilon^{C B 7-D S M I H 2+}\left[D S M I H^{2+}\right]
$$

If we consider the protonation of $\mathrm{DSMI}^{+}$on the inclusion complex and at the $\mathrm{pH}$ of the medium $\approx 7$ the protonated specie of $\mathrm{DSMIH}^{2+}$ can be neglected in the absence of CB7.

$$
A_{o b s}=\varepsilon^{D S M I+}\left[D S M I^{+}\right]+\varepsilon^{C B 7-D S M I+}\left[C B 7-D S M I^{+}\right]+\varepsilon^{C B 7-D S M I H 2+}\left[C B 7-D S M I H^{2+}\right]
$$

The $A_{\mathrm{obs}}$ (equation S-2) can be expressed in terms of binding constants and total concentrations of CB7 and DSMI+ (equation S-3).

$$
A_{o b s}=\frac{A+B[C B 7]}{1+K_{a p p}[C B 7]}
$$

where

$$
\begin{gathered}
A=\varepsilon^{D S M I+}\left[D S M I^{+}\right]_{T} \\
B=\left[D S M I^{+}\right]_{T}\left(\varepsilon^{C B 7-D S M I+} K_{D S M I+}+\frac{\varepsilon^{C B 7-D S M I H 2+}\left[H^{+}\right] K_{D S M I H 2+}}{K_{a}}\right. \\
K_{a p p}=K_{D S M I+}+\frac{K_{D S M I H 2+}\left[H^{+}\right]}{K_{a}}
\end{gathered}
$$

Equation S-3 gave an excellent fit to the experimental data (Figure S1-right), from which were obtained the value of the apparent binding constant, $K_{\text {app }}=(4.5 \pm 0.3) \times 10^{6}$ $\mathrm{M}^{-1}$.

The influence of CB7 on the absorption spectra of DSMI+ was studied in the presence of SB3-14 (Figure S2).
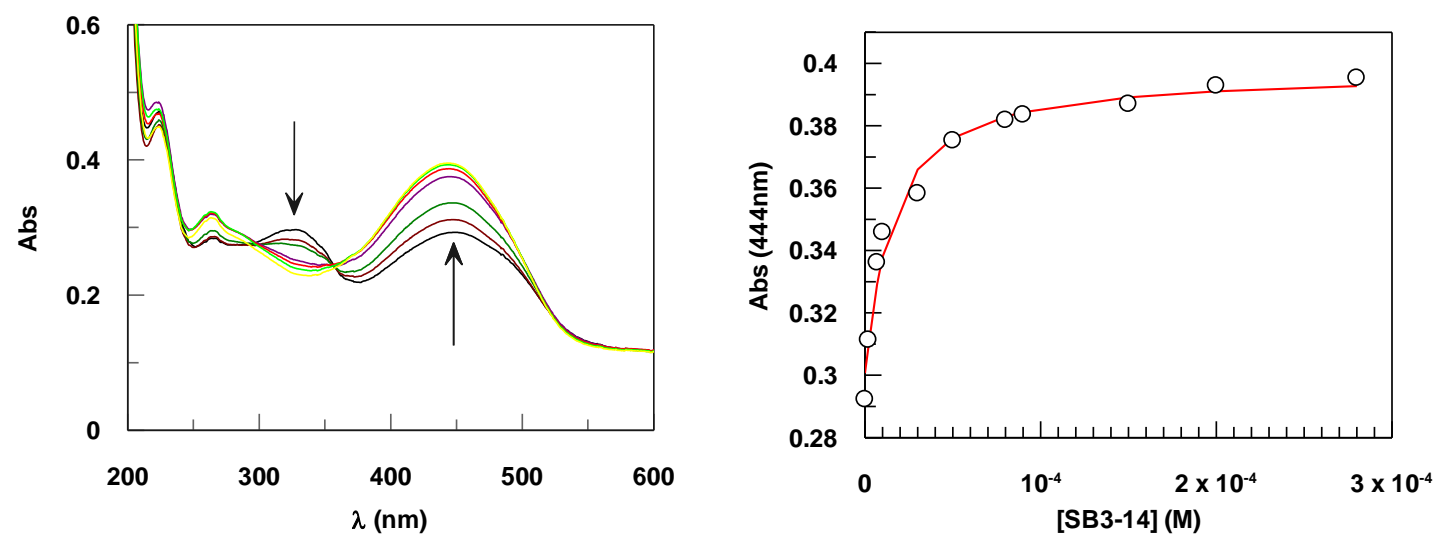

Figure S2. Influence of SB3-14 concentration on the absorption spectra of DSMI+ in the presence of CB7 at neutral $\mathrm{pH}$ and $25.0^{\circ} \mathrm{C}$. [CB7] $=1.2 \times 10^{-5} \mathrm{M}$; [DSMI $\left.{ }^{+}\right]=1.17 \times 10^{-5} \mathrm{M}$. 
To solve equation S-3 it is necessary to know the concentration of uncomplexed CB7, [CB7] f, for each surfactant concentration. The concentration of uncomplexed CB7 can be obtained by means a simulation procedure, supposing that the complexes formed with the CB7 has a stoichiometric ratio 1:1. The complexation constants of the $\mathrm{DSMI}^{+}$by CB7 and for the surfactant monomers by CB7 are expressed as (equations S-7):

$$
\begin{gathered}
K_{D S M I+}=\frac{\left[C B 7-D S M I^{+}\right]}{[C B 7]\left[D S M I^{+}\right]} \quad K_{D S M I H 2+}=\frac{\left[C B 7-D S M I H^{2+}\right]}{[C B 7]\left[D S M I H^{2+}\right]} \quad K_{a}=\frac{\left[D S M I^{+}\right]\left[H^{+}\right]}{\left[D S M I H^{2+}\right]} \\
K_{a^{\prime}}=\frac{\left[C B 7-D S M I^{+}\right]\left[H^{+}\right]}{\left[C B 7-D S M I H^{2+}\right]} \quad K_{1: 1}=\frac{[C B 7-S]}{[S][C B 7]}
\end{gathered}
$$

The mass balance for the total concentrations of CB7, $\mathrm{DSMI}^{+}$and surfactant are given by

$$
\begin{gathered}
{[S]_{T}=[S]+[C B 7-S]} \\
{\left[D S M I^{+}\right]_{T}=\left[D S M I^{+}\right]+\left[C B 7-D S M I^{+}\right]+\left[C B 7-D S M I H^{2+}\right]} \\
{[C B 7]_{T}=[C B 7]+\left[C B 7-D S M I^{+}\right]+\left[C B 7-D S M I H^{2+}\right]+[C B 7-S]}
\end{gathered}
$$

The combination of these equations with the binbing constants gives a third order equation for the concentration of uncomplexed CB7 (equation S-11):

$$
a[C B 7]_{f}^{3}+b[C B 7]_{f}^{2}+c[C B 7]_{f}+d=0
$$

Where

$$
\begin{gathered}
a=K_{a p p} K_{1: 1} \\
b=K_{1: 1}+K_{a p p}+K_{1: 1} K_{a p p}\left(\left[D S M I^{+}\right]_{T}+[S]_{T}-[C B 7]_{T}\right) \\
c=K_{a p p}\left(\left[D S M I^{+}\right]_{T}-[C B 7]_{T}\right)+K_{1: 1}\left([S]_{T}-[C B 7]_{T}\right)+1 \\
d=-[C B 7]_{T}
\end{gathered}
$$

The equation S- 11 was solved for different values of $K_{1: 1}$, in order to obtain [CB7]f. The value of $K_{1: 1}, K_{1: 1}=(4.5 \pm 0.1) \times 10^{6} \mathrm{M}^{-1}$, for which we obtain the best rootmean-square deviation values in the fitting of equation S-3 (Figure S-2 right) to the experimental results, was taken as optimal.

[1] N. Saleh, A. L. Koner, W. M. Nau, Angew. Chem. Int. Ed. 2008, 47, 5398-5401 


\section{TCOSY spectrum for NMR assignment}

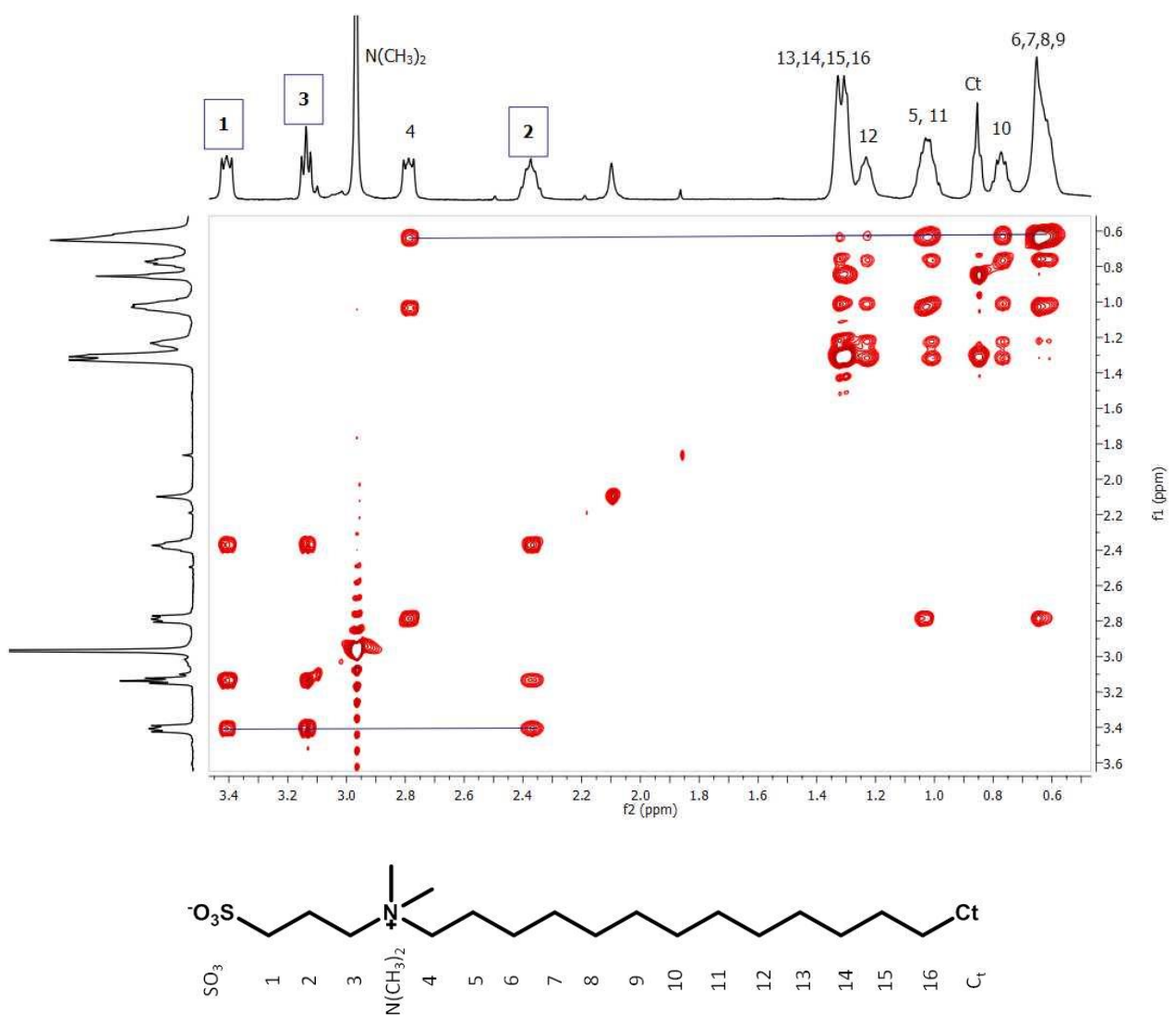

Figure S3. TCOSY spectrum of SB3-14 (0.5mM) in the presence of CB7 (1mM). Carbon atoms are numbered starting at the sulfonate group. 


\section{NMR evidence for 2:1 host:guest complexes}

Figure S4 shows the NMR titration of SB3-14, $[\mathrm{SB} 3-14]=0.50 \mathrm{mM}$, by successive addition of CB7. Cucurbituril addition for ratios [CB7]/[SB3-13] smaller than one leads to the observation of two sets of resonances, corresponding to the free guest and a new species, SB3-14:CB7, the host guest complex of sulfobetaine and CB7. The simultaneous observation of resonances for these two species indicates that the host-exchange process is slow on the time scale of the NMR experiments. Once the amount of added CB7 reaches a full equivalent, the peaks for the host:guest complex, SB3-14:CB7, become fully developed. The presence of CB7 leads to substantial upfield (which is a well-stablished indication that guest is included into the CB7 cavity) and dowfield ${ }^{[2]}$ (revealing that protons are held in the proximity of the carbonyl-laced host portal but outside the cavity) shifts for sulfobetaine proton resonances. We also noted that each of the two doublets corresponding to the methylene protons on the CB7 host is split into two overlapping doublets, reflecting the environmental differences between the two CB7 portals upon inclusion of SB3-14. In other words, one of the CB7 portals is exposed to the dimethylammonium side arm while the other one is not.

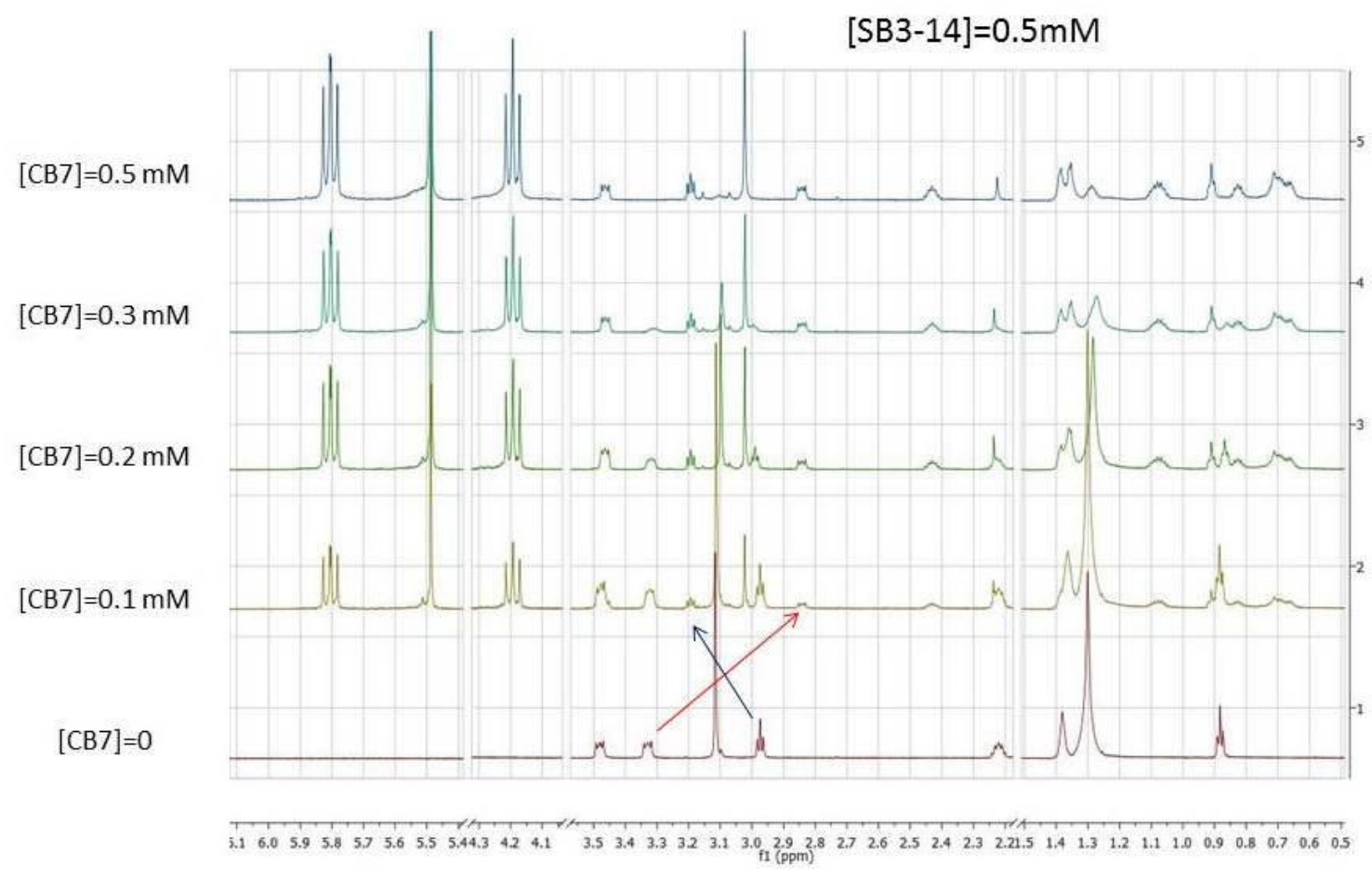

Figure S4. ${ }^{1} \mathrm{H}$ NMR spectral regions of SB3-14 $(0.50 \mathrm{mM})$ with $0 ; 0.1 ; 0.2 ; 0.3$ and $0.5 \mathrm{mM}$ of CB7 in $\mathrm{D}_{2} \mathrm{O}$ at $25^{\circ} \mathrm{C}$. 
Figure S5 shows the NMR evolution by further addition of CB7. As can be observed a new NMR signal can be observed at 3.15ppm. As will be shown this signal corresponds to the 2:1 host:guest complex obtained under slow exchange regime.

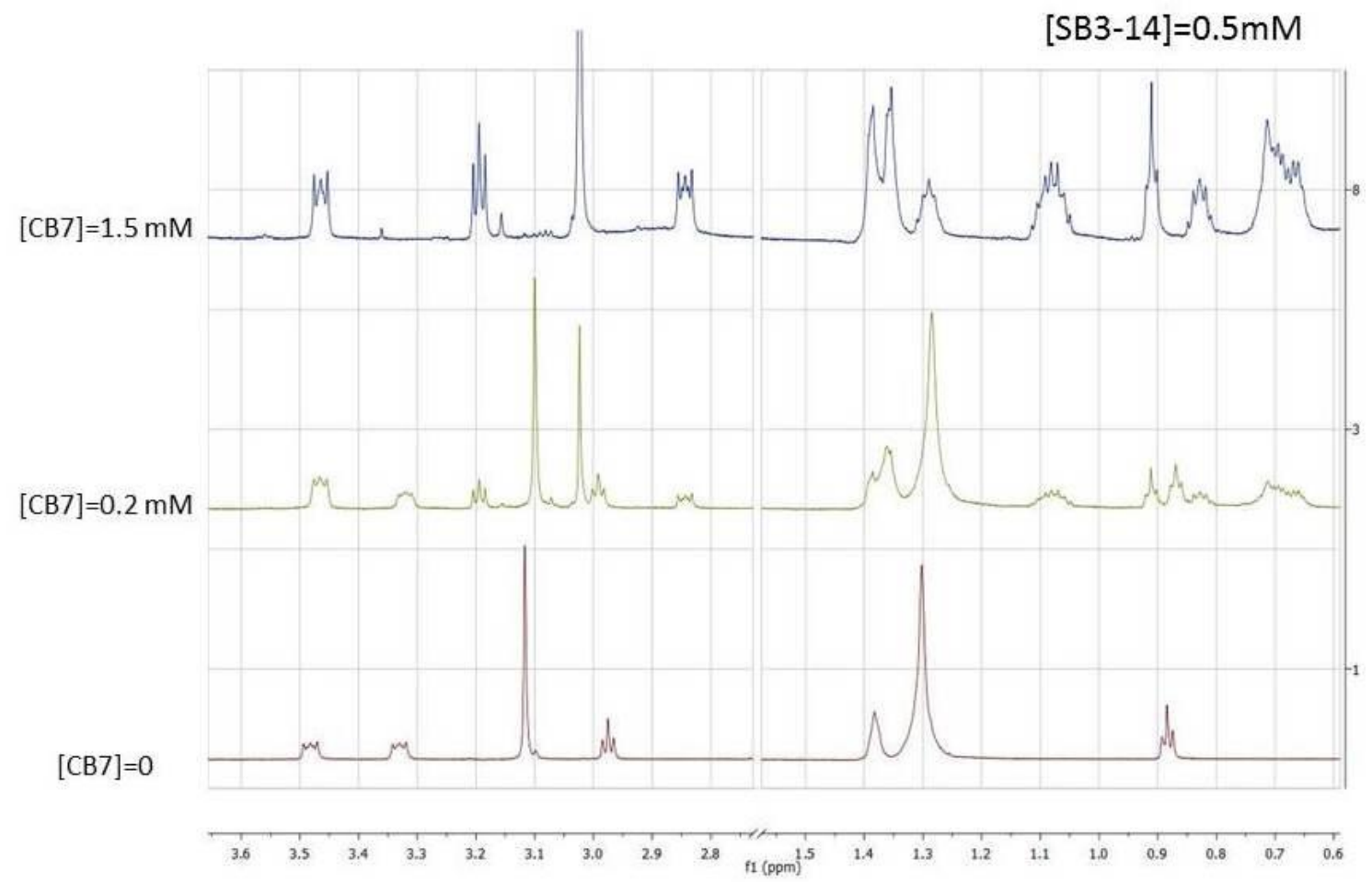

Figure S5. ${ }^{1} \mathrm{H}$ NMR spectral regions of SB3-14 $(0.50 \mathrm{mM})$ with $0 ; 0.2$ and $1.5 \mathrm{mM}$ of $\mathrm{CB} 7$ in $\mathrm{D}_{2} \mathrm{O}$ at $25^{\circ} \mathrm{C}$. 
Assignation of the NMR signal observed at 3.15ppm have been done by a 2D edited-HSQC experiment where signals corresponding to $\mathrm{CH}_{2}$ groups appears in blue and those corresponding to $\mathrm{CH}_{3}$ and $\mathrm{CH}$ ones appear in red. As can be observed in next figure both signals at $3.15 \mathrm{ppm}$ and $3.03 \mathrm{ppm}$ share the same ${ }^{13} \mathrm{C}$ chemical shift. This proton-carbon correlation is a good indicative that both signals correspond to a $\mathrm{CH}_{3}$ group bounded to an ammonium nitrogen atom.

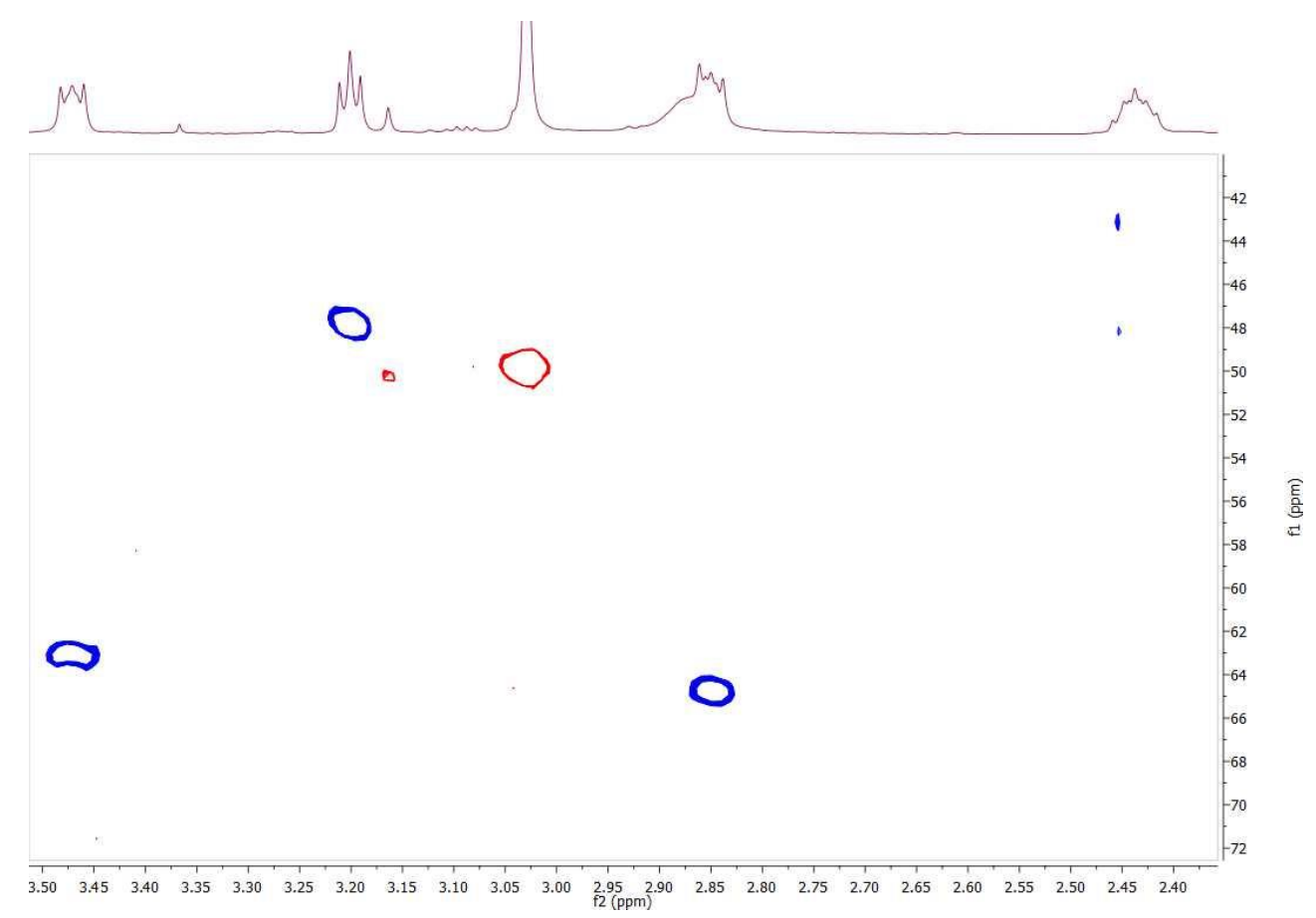

Figure S6. Part of the 2D edited-HSQC spectrum for a mixture of SB3-14 (0.50mM) and CB7 (1.5 mM) in $\mathrm{D}_{2} \mathrm{O}$ at $25^{\circ} \mathrm{C}$. 
In order to corroborate that the signal at $3.15 \mathrm{ppm}$ corresponds to a $\mathrm{CH}_{3}$ group bounded to an ammonium group we carried out STD experiments. First at all we demonstrate that the selectivity or the irradiation in the STD experiment is correctly calibrated. When irradiating the triplet at $3.20 \mathrm{ppm}$ it did not affect to the closet peaks at 3.15ppm neither to the ${ }^{+} \mathrm{NMe}_{2}$ peak at 3.03ppm (see Figure S7).

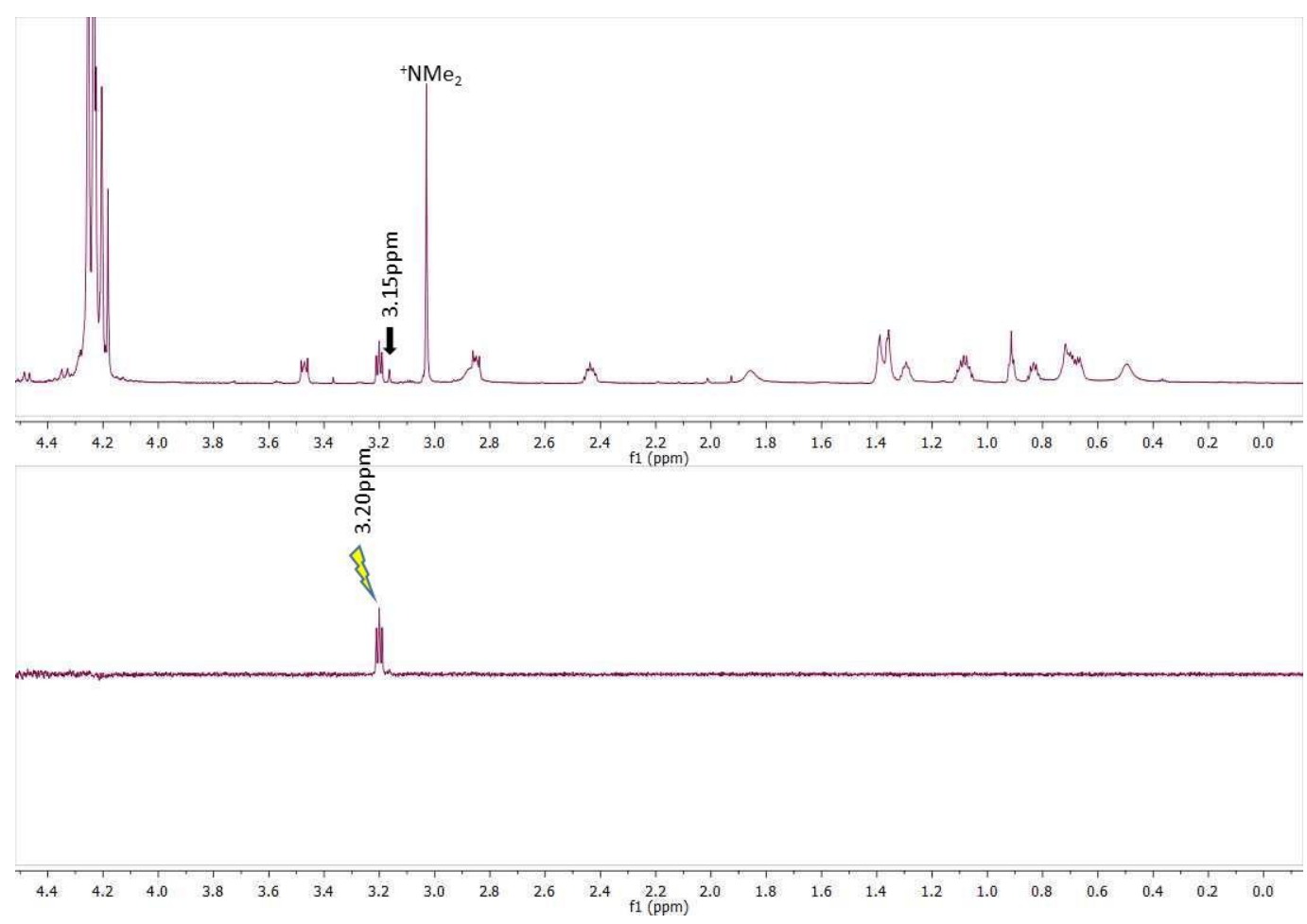

Figure S7. $\mathrm{STD}_{\text {off }}$ and $\mathrm{STDoff}_{\text {-on }}$ spectra recorded upon saturation of signal at $3.20 \mathrm{ppm}$ for a mixture of SB3-14 $(0.50 \mathrm{mM})$ and $\mathrm{CB} 7(1.5 \mathrm{mM})$ in $\mathrm{D}_{2} \mathrm{O}$ at $25^{\circ} \mathrm{C}$. 
Figure S8 shows the reference STD ${ }_{\text {off }}$ spectrum and the STD off-on spectrum when the on-saturation was applied at 3.15ppm, a region where the ${ }^{+} \mathrm{NMe}_{2}$ protons of SB314 in the 2:1 host:guest complex are present. As can be observed, an important transfer to the ${ }^{+} \mathrm{NMe}_{2}$ group (corresponding to the 1:1 host:guest complex) is observed in agreement with the slow exchange regime for CB7:SB3-14 host:guest complex. Signal at 3.15ppm corresponds to the ${ }^{+} \mathrm{NMe}_{2}$ group of the betaine in the 2:1 complex. After saturation the 2:1 complex exchange to the $1: 1$ complex and transfer of magnetization is observed to signal a 3.03ppm (signal corresponding to $+\mathrm{NMe}_{2}$ group in the 1:1 complex).
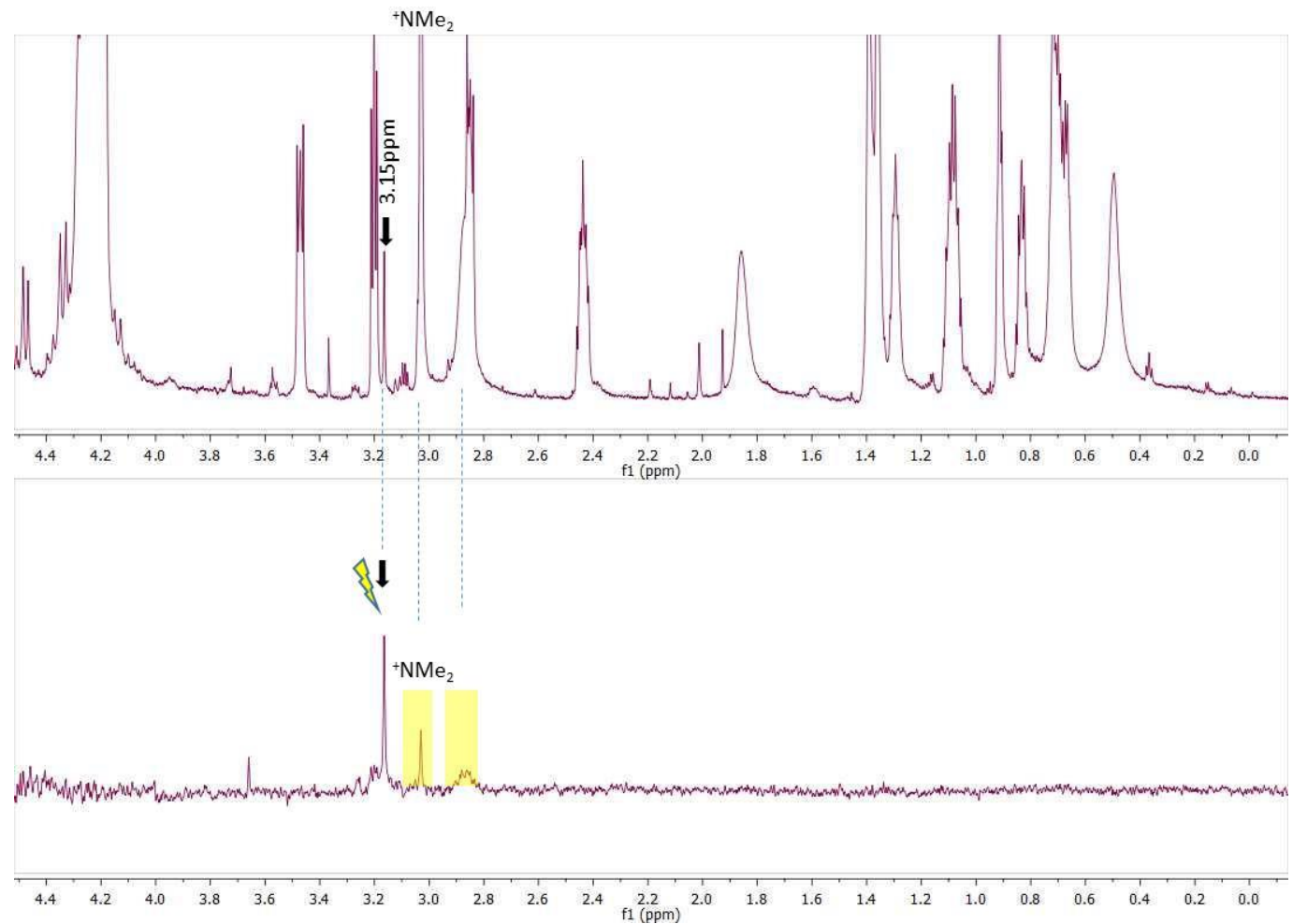

Figure S8. $\mathrm{STD}_{\text {off }}$ and $\mathrm{STDoff}_{\text {-on }}$ spectra recorded upon saturation of signal at $3.15 \mathrm{ppm}$ for a mixture of SB3-14 (0.50mM) and CB7 (1.5 $\mathrm{mM})$ in $\mathrm{D}_{2} \mathrm{O}$ at $25^{\circ} \mathrm{C}$. 
The STD spectra obtained for the host:guest complexes by irradiation of the signal ${ }^{+} \mathrm{NMe}_{2}$ of the 2:1 complex at a series of saturation times are shown in Figure S9. It can be observed the magnetization transfer from ${ }^{+} \mathrm{NMe}_{2}$ in the $2: 1$ complex to ${ }^{+} \mathrm{NMe}_{2}$ in the 1:1 complex as a function of the saturation time. It should be noted that both 2:1 and 1:1 complex are formed under slow exchange regime in comparison with timescale for NMR experiments. Consequently dissociation of 2:1 complex to 1:1 during the saturation time should be responsible for the transfer of magnetization.

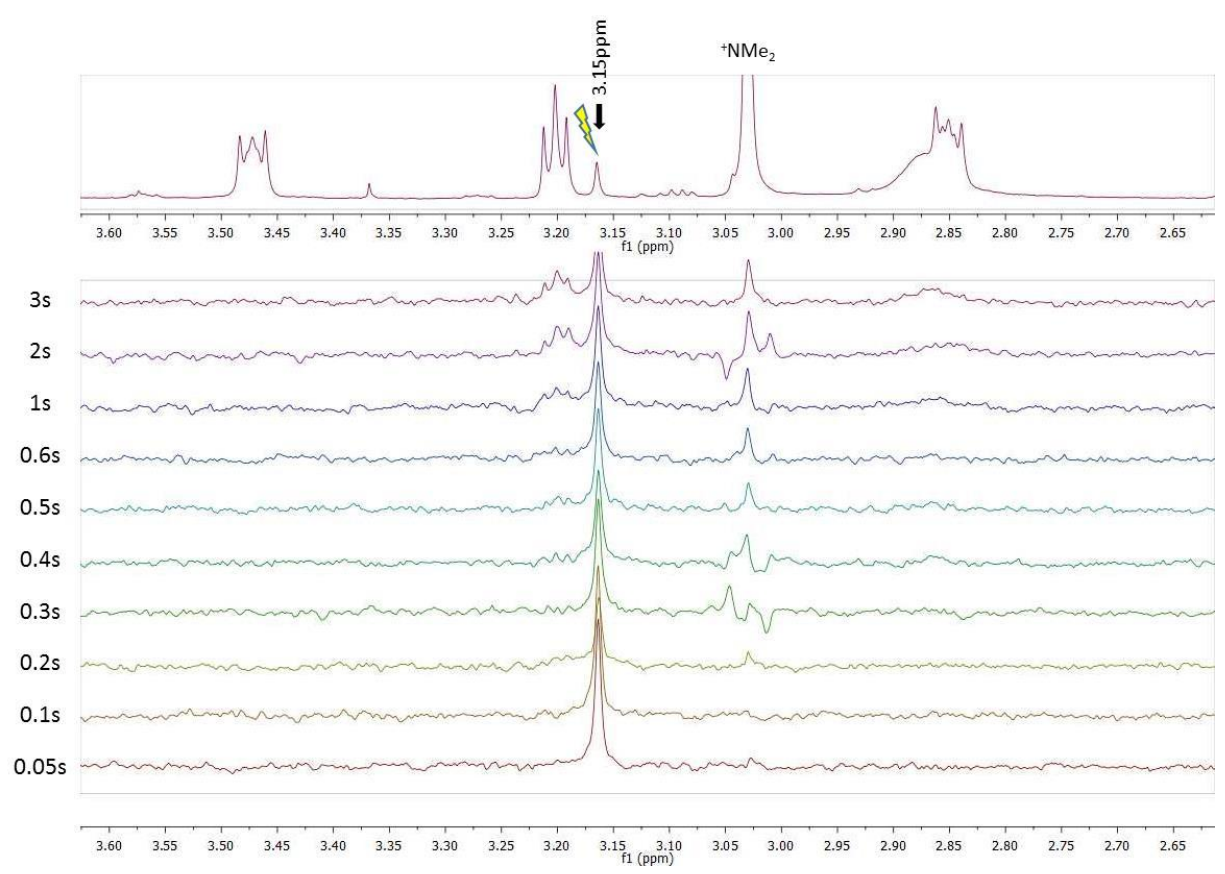

Figure S9. $\mathrm{STD}_{\text {off }}$ and $\mathrm{STDoff-on}$ spectra recorded upon saturation of signal at $3.15 \mathrm{ppm}$ for a mixture of SB3-14 $(0.50 \mathrm{mM})$ and $\mathrm{CB} 7(1.5 \mathrm{mM})$ in $\mathrm{D}_{2} \mathrm{O}$ at $25^{\circ} \mathrm{C}$. The saturation times are indicated.

As a conclusion we can observe three different signals for the ${ }^{+} \mathrm{NMe}_{2}$ group in SB314: (i) signal corresponding to uncomplexed SB3-14 at $3.10 \mathrm{ppm}$; (ii) signal corresponding to SB3-14 in the $1: 1$ complex at $3.03 \mathrm{ppm}$ and (iii) signal corresponding to the SB3-14 in the 2:1 complex at 3.15ppm. Coexistence of these signals (3.10 and 3.03ppm for [SB3-14]/[CB7]>1 and 3.03 and 3.15 ppm for [SB3$14] /[\mathrm{CB} 7]<1$ ) are in agreement with formation of these complexes under slow exchange regime in the NMR timescale.

[2] Barrow, S. J.; Kasera, S.; Rowland, M. J.; del Barrio, J.; Scherman, O. A. Chem. Rev. 2015, 115, 12320-12406. 


\section{DLS characterization of SNPs formation and disruption}
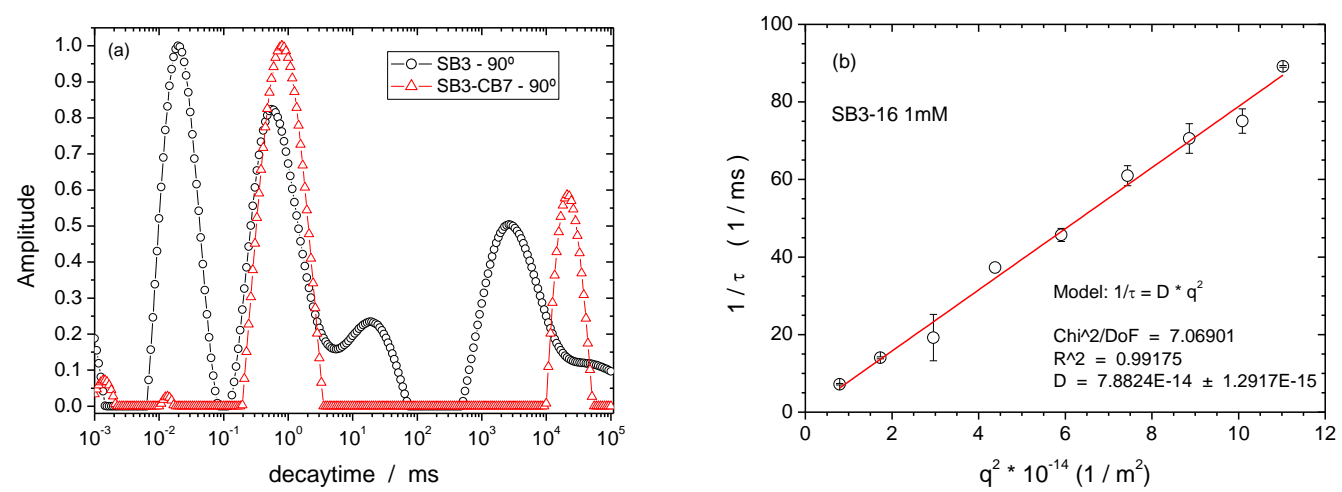

Figure S10: DLS data. (Left) Comparison of the decay time distribution for SB3-16 micelles and CB7:SB3-16 inclusion complex; (Right) determination of the diffusion coefficient of the SB3-16 micelles. [SB3-16] $=1 \mathrm{mM}$; [CB7] $=1 \mathrm{mM}$.
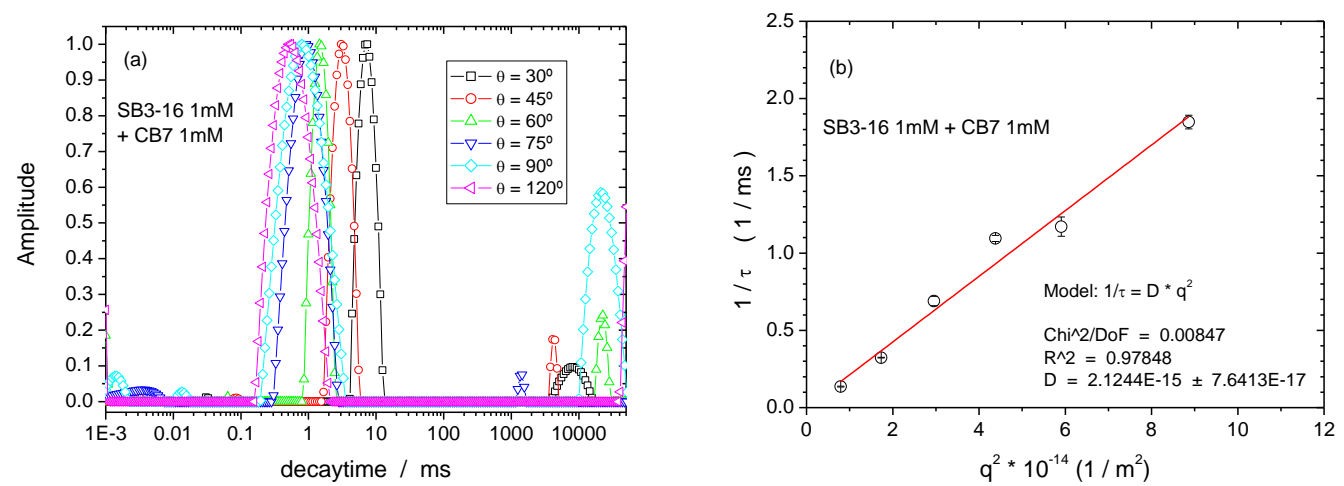

Figure S11: DLS data for CB7:SB3-16 inclusion complex. (Left) angular dependence; (Right) determination of the diffusion coefficient of the inclusion complex. [CB7] $=1 \mathrm{mM} ;[\mathrm{SB} 3-16]=1 \mathrm{mM}$. 


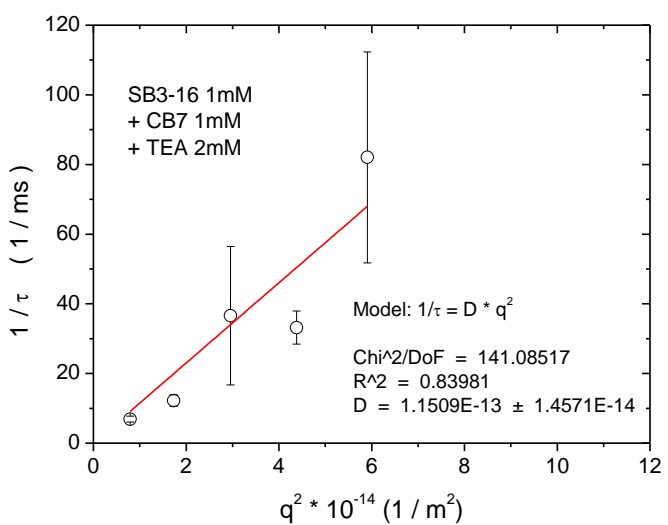

Figure S12: DLS data of recovered SB3-16 micelles after addition of 2mM TEA in order to break the SB3-16 - CB7 supramolecular nanoparticles. 


\section{Size and Zeta potential evolution with time and composition}
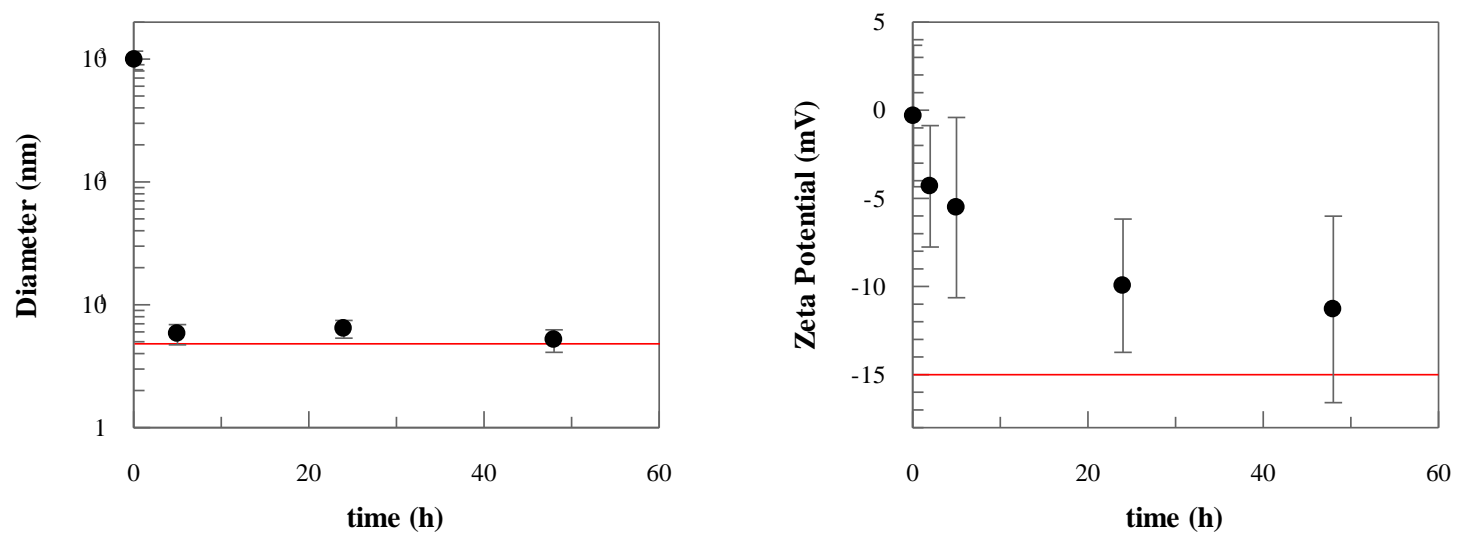

Figure S13: (Left) Hydrodynamic number-weighted size evolution on time for supramolecular nanoparticles derived from SB3-16 and CB7 at $25^{\circ} \mathrm{C}$ obtained for molar ratio [SB3-16]/[CB7]=4. (Right) Z-potential evolution on time for supramolecular nanoparticles derived from SB3-16 and $\mathrm{CB} 7$ at $25^{\circ} \mathrm{C}$ obtained for molar ratio $[\mathrm{SB} 3-16] /[\mathrm{CB} 7]=4$. Red line shows the size and Z-potential of SB3-16 micelles.
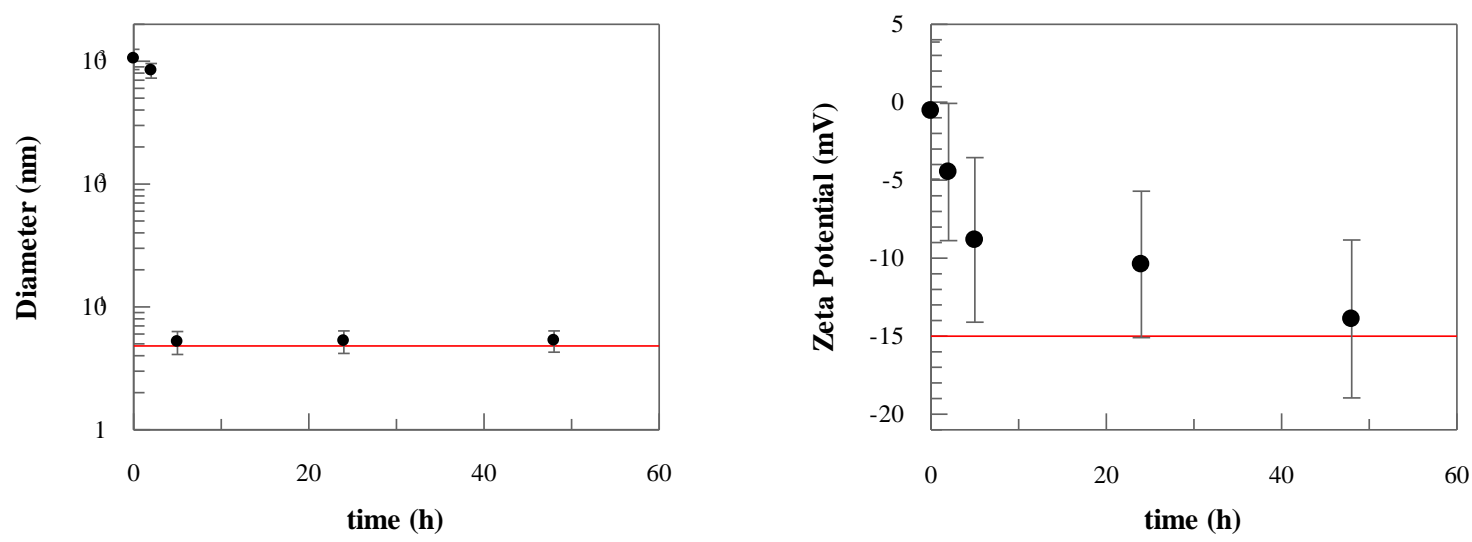

Figure S14: (Left) Hydrodynamic number-weighted size evolution on time for supramolecular nanoparticles derived from SB3-16 and $\mathrm{CB} 7$ at $25^{\circ} \mathrm{C}$ obtained for molar ratio [SB3-16]/[CB7]=5,3. (Right) Z-potential evolution on time for supramolecular nanoparticles derived from SB3-16 and CB7 at $25^{\circ} \mathrm{C}$ obtained for molar ratio $[\mathrm{SB} 3-16] /[\mathrm{CB} 7]=5,3$. Red line shows the size and Z-potential of SB3-16 micelles. 


\section{DLS experiments in the presence of $\mathrm{CF}$}

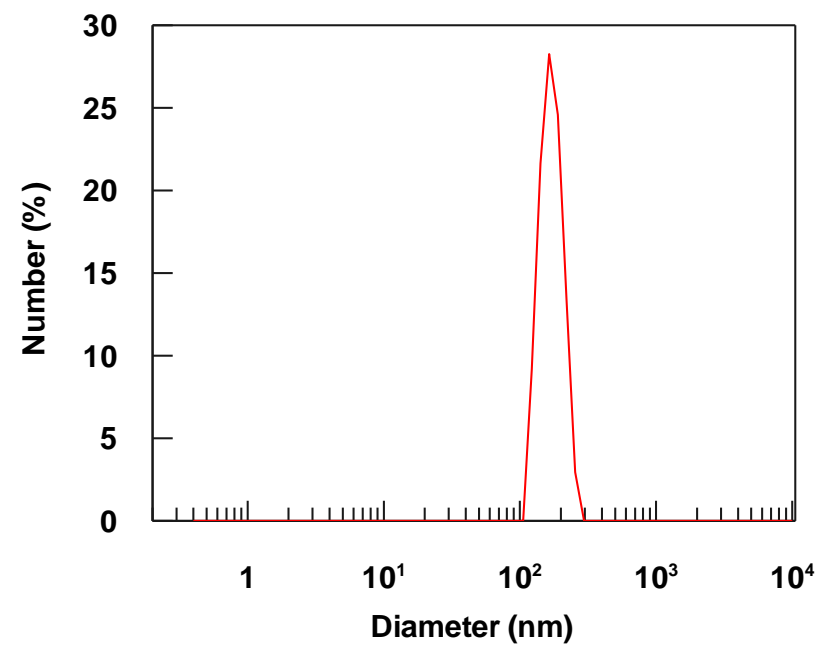

Figure S15. DLS measurements showing the number-weighted size distribution (diameter $172 \mathrm{~nm}$ ) of SNPs with encapsulated CF.

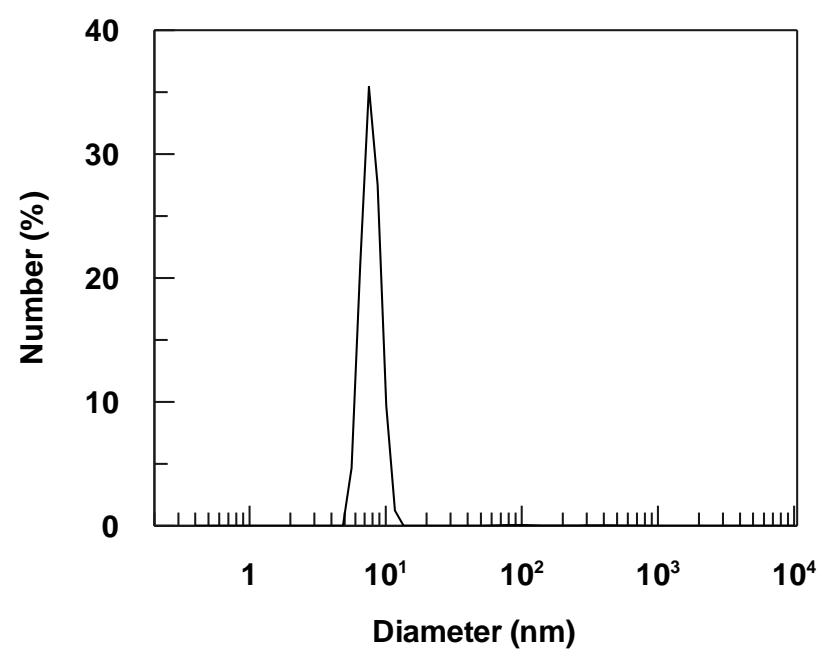

Figure S16. DLS measurements showing the number-weighted size distribution for SB3-16 micelle (diameter $7.8 \mathrm{~nm}$ ) upon disruption of SNPs by TEA addition with encapsulated CF. 


\section{CF fluorescence in the presence of SB3-16 micelles}

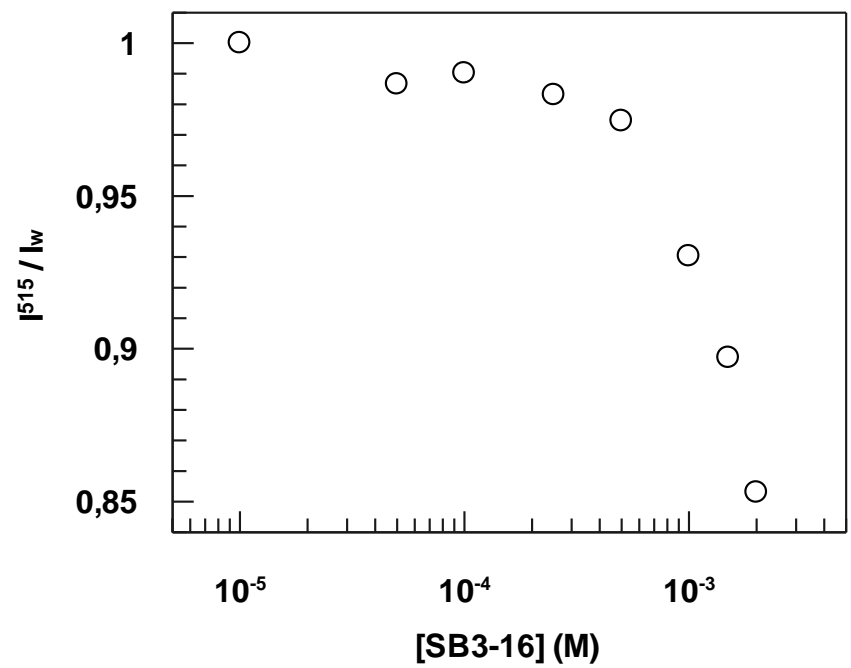

Figure S17. Quenching of CF fluorescence by addition of SB3-16 micelles. $[\mathrm{CF}]=1 \times 10^{-7} \mathrm{M}$

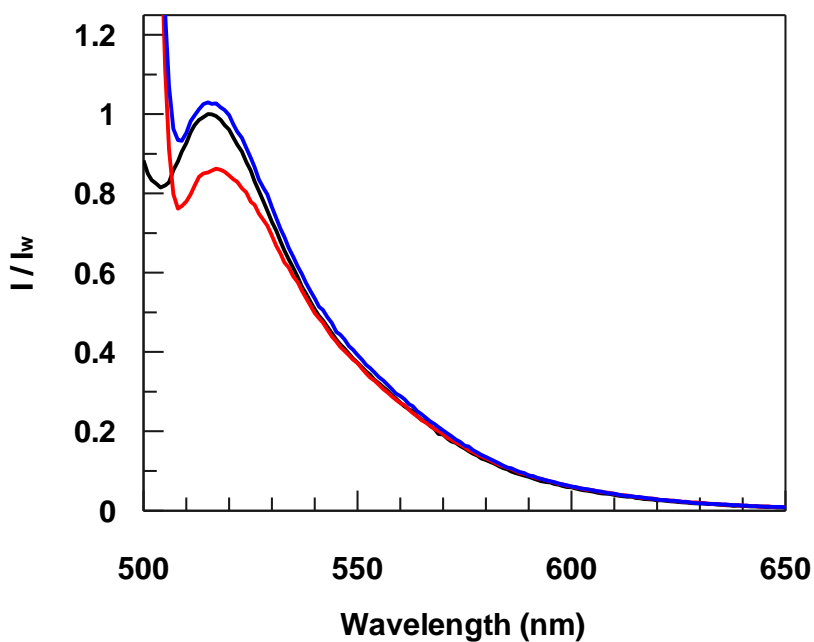

Figure S18. Emission spectra of CF encapsulated in SB3-16 micelles upon addition of $\alpha$-CD. (black line) CF emission spectrum in bulk water; (red line) CF emission spectrum in SB3-16 micelles and (blue line) $\mathrm{CF}$ emission spectrum upon addition of $\alpha-\mathrm{CD}$ to SB3-16 micelles at $25^{\circ} \mathrm{C}$. $[\mathrm{CF}]=1 \times 10^{-7} \mathrm{M}$; [SB3-16]= $2 \times 10^{-3} \mathrm{M} ;[\alpha-\mathrm{CD}]=1 \times 10^{-2} \mathrm{M}$. 